\title{
Overcoming Decision Uncertainty and Compromise Effect in Issues Pertaining to Health through TICOS - Treatment Information and Cost Optimization System
}

\author{
Sathya Priya Balasegaran \\ Master's in Business Administration, \\ VIT Business School, Vellore, Tamil Nadu, India
}

\author{
Aarthy Sampath \\ Master's in Business Administration \\ VIT Business School, Vellore, Tamil Nadu, India
}

\begin{abstract}
The Compromise Effect states that a consumer is more likely to choose the middle option of a choice set rather than the extremes, when they are rational and are provided with complete information about a product or service. The effect varies in an incomplete information scenario, especially in a sensitive decision making need such as a health care emergency. Affordability and awareness play a major role. The insecurity that follows eithers leads to incurring huge expenses or to a compromise over service quality. Further, huge variations in the level of service in terms of quality and price exist among health care providers. The ambiguity in consultation process, which evokes a sense of diffidence among patients, is a concern to be addressed. Health informatics is an emerging field that mines the best usage of Information Technology and delivers tremendous quality service to customers. In line with this is the proposed system, the Treatment Information and Cost Optimization System (TICOS), which enables non-biased service in terms of consultation, clarity and pricing, thereby bringing in transparency in the process. Integration of the system across all hospitals in a region can be done by embedding the system with regulatory bodies like WHO and IMA.
\end{abstract}

\section{General Terms}

Information systems, Healthcare, Health informatics, Customer awareness, Decision Uncertainty.

\section{Keywords}

Compromise Effect, Decision Making, Cost Optimization, Consumer Affordability.

\section{INTRODUCTION}

Health care and the attention given to it has been invariably a constant part of a person's lives. Thanks to the boon of technology growth and the advancement of medical care, for people with chronic diseases and life-threatening illnesses, it is quintessential that they remain in touch with their doctors for their life-prolonging treatments [1]. A few existing IT solutions for health care, that have been running successfully in various parts of India (and one internationally) are explained in detail, in the following paragraphs.

HISP India [2], a global network currently operational in the national level, provides open source software to implement an integrated Health Information system as a strategic resource. It also utilizes tools for public health surveys and analysis, which in turn, can be used in administrative and health management programs.

Cognizant's Health Care Solution strives to reengineer its business strategy, through its "Health Intelligence" [3], to enable health organizations achieve quality improvements in real-time at the point of care. Big Data is seemingly going to be effective in changing the future of the Healthcare ecosystem.

In the customer's (here, patient's) perspective, fixed with a clear goal in mind, health care decisions are taken not only with a logical mind, but will also have spiritual and emotional sides that can come in the way. Needless to say, that is why they are called "difficult decisions". But without doubt, the financial aspect of the same can also be considered, i.e., a customer, if he is focused on his betterment, is ready to pay to the maximum of his affordability, to avail the best treatment possible. Now, the health institution may at times, try to manipulate the patient to its advantage, by charging exorbitant rates. This places patients at helpless situations, and a reliable, trustworthy regulatory system will be of great use.

Birlamedisoft Healthcare Softwares [4] runs one of the best Hospital Information Management Systems (HIMS) that develops real time web based solutions for Hospitals, medical departments like Pathology, Imaging centers and so on. Innovation and Smart Execution, together with ingenuity and smart execution, seems to be the imbibed tagline and the competitive edge to the company.

Mayo Clinic, a US based hospital chain, that was awarded the best hospital in the year 2014-2015, has launched a $\$ 3$ billion campaign to set new world standard in health care. It is also known for its exceptional service quality to the customers, with special focus on immediate care seeking patients. Though they don't have a stringent medical software solution to cater to their customers, President Obama has often quoted Mayo Clinic for its marketing excellence, independent thinking, outstanding service and performance and core focus on patient care and satisfaction.

To conclude, all these health care institutions and solutions have a well-established fame for their competency, however, the consumer behavior based on the price offering aspect seems to subtly demand more focus. In this paper, a proper information system solution is proposed, that tries to eliminate the compromise effect, and provide optimized and cost effective treatment to the needy people.

\subsection{Decision Uncertainty}

In general, decision making is nothing but reducing the uncertainty [5] in the number of solution options, by gaining sufficient knowledge of the options to allow a suitable selection from them. At times, an increasing sense of uncertainty, due to events occurring locally or globally can 
grab a lot of media attention. It may also reflect a changing environment, and accommodating these changes provides the opportunity to increase decision making effectiveness.

During high decision uncertainty, it is better to take smaller, familiar and secure steps. Knowledge makes the new seem more familiar, reducing separation and anxiety. One must also avoid unneeded risk. For example, when there is economic uncertainty, postpone investing in a new car. Combining risks from multiple decisions (e.g., choosing to get married and change jobs at the same time) can create confusion, increase stress, and make it difficult to learn from unsuccessful outcomes. Also, knowing the worst situation (worst case scenario) is survivable, can ease this uncontrollable fear. The ability to deal with uncertain information in a straightforward and natural way helps improve the quality of planning [6]; enable rationality in responses to unexpected events; provide more situation awareness; and allow a better understanding of available options. These enhancements to the decision making process will help people and machines to make better decisions in less time and with lower costs. Estimating the negative and positive consequences of the risk or uncertainty can encourage taking risks for good opportunities only.

The underlying premise of effective decision making is that the decision maker knows their needs and desires, and also invests in keeping options open. As knowledge is obtained, number of options is reduced and certainty is increased. Besides, effective management, monitoring and adaptation of decisions are also useful.

It is also best to avoid emotional risk taking, and to take risks for the right reasons based on clear, calm, and rational thought. This is the primary type of risk taking that is involved in critical health care treatments.

\section{2 "Compromise Effect" of Consumers in Health Care}

Compromise effect and decision uncertainty go hand in hand and are typically a cause and effect relationship. Compromise effect (introduced by Simonson in 1989) states that a consumer when presented with a set of three alternatives choice set is more inclined to choose the middle option out of the three when they are rational and are provided with complete information about the product or the service. i.e., when I am choosing between a small radio A and a midsized radio $\mathrm{B}$, I would choose $\mathrm{A}$; but if a large radio $\mathrm{C}$ is added, $\mathrm{I}$ would "psychologically be inclined" to choose B instead of A. Hence it is evident that affordability and customer awareness play a major role.

Consumers must have easily available, accurate, and timely information to make informed choices and navigate within a complex health care system. The available choices of alternatives, the pros and cons and its importance must be clearly stated. Contrary to the consumer-driven approach, however, the evidence demonstrates that having an abundance of information does not always translate into its being used to inform choices. The challenge is not merely to communicate accurate information to consumers, but to understand how to present and target that information so that it is actually used in decision-making.

The types of decisions that consumers and patients are making are also delineated, together with, the barriers to using information effectively in choice, especially in a crucial decision making need like that of healthcare. The fact of compromise effect can do good for perishable goods but not life, hence a standardized benchmark in terms of process and cost decision [7] that reveals accurate and relevant information to the patients to make rational decision is the need of the hour, which might lead to effectiveness in the way health care services are perceived by the patients and the public as a whole. Mobile application development is the window where one embeds coding procedures, add-ins and plug-ins, interactive controls and texts into task specific applications, to run on personal and enterprise digital assistants, tablets and mobile phones. Mobile application development is similar to web application development, the only difference being the former has to be ensured of its compatibility with the target device. For instance, one could develop gaming apps for an iPhone, for a unique gaming experience with its accelerometer.

\subsection{Research Objective}

To propose an information system: TICOS-Treatment Information and Cost Optimization System that can be implemented in the current scenario at both private and government hospitals by embedding it to the existing information systems. The prime motive of the system as a whole is to provide patients with complete information about services and costs incurred and thereby enabling them with a sense of trust and satisfaction before they agree and are exposed to the actual treatment process. The health care service across regions must be standardized, transparent and unambiguous for which TICOS would be serving as an enabler by itself.

\section{STRUCTURE OF THE PAPER}

The paper is organized as follows:

Section 3 discusses the Related Literature review Work done. Section 4 presents the existing system, followed by Section 5 , the TICOS system and its architecture. Section 6 introduces the implementation of Proposed System, followed by integration of TICOS in hospitals in Section 7. The advantages, disadvantages of the system and its prerequisites for successful real time implementation have also been mentioned in the same section followed by future enhancements in Section 8 and conclusion of the paper in Section 9 .

\section{LITERATURE REVIEW}

The working environment in health care organizations is characterized by its demand for highly dynamic process and labour management in which (a) medical personnel are generally associated with several disparate types of tasks, (b) service location and service personnel change frequently, (c) highly uncertain environment where emergency issues could arise at any time, and (d) the stakes are high since invaluable human lives are involved. There is an urgent need from both researchers and health care organizations to develop reasonable management strategies for maintaining a good balance between efficient management and superior medical service quality [8]. Uncertainty is a pervasive and important problem that has attracted increasing attention in health care, given the growing emphasis on evidence-based medicine, shared decision making, and patient-centred care. However, the present understanding of this problem is limited, in part because of the absence of a unified, coherent concept of uncertainty. There are multiple meanings and varieties of uncertainty in health care that are not often distinguished or acknowledged although each may have unique effects or 
warrant different courses of action [9]. The budget for health care is fixed and decisions are based on incremental cost effectiveness ratios (ICERs), discounting costs and health gains at the same rate is correct only if the threshold remains constant [10]. Expecting growth in the consumption value of health does not itself justify differential rates but implies a lower rate for both. However, whether one believes that the objective should be the maximisation of the present value of health or the present consumption value of health, adopting the social time preference rate for consumption as the discount rate for costs and health gains is valid only under strong and implausible assumptions about values and facts [11].

\section{EXISTING SYSTEM}

The current system consists of the following:

As healthcare information systems become crucial for clinical care and hospital operations, Information Officers are under significant pressure to prioritize their resources appropriately, to implement this. The evolution of health care systems has been as follows:

Table 1. Evolution of Hospital Information Systems

\begin{tabular}{|c|c|c|c|}
\hline Decade & $\begin{array}{c}\text { Health care } \\
\text { Drivers }\end{array}$ & IT Drivers & $\begin{array}{c}\text { Resulting } \\
\text { HIT }\end{array}$ \\
\hline $1960 \mathrm{~s}$ & $\begin{array}{l}\text { Medicaire/ } \\
\text { Medicaid }\end{array}$ & $\begin{array}{l}\text { Expensive } \\
\text { mainframe } \\
\text { and storage }\end{array}$ & $\begin{array}{c}\text { Shared } \\
\text { hospital } \\
\text { accounting } \\
\text { system }\end{array}$ \\
\hline 1970s & $\begin{array}{l}\text { Hospital } \\
\text { wide } \\
\text { communicati } \\
\text { on systems }\end{array}$ & $\begin{array}{c}\text { Smaller } \\
\text { computers } \\
\text { with } \\
\text { improved } \\
\text { terminals } \\
\text { and } \\
\text { connectivity }\end{array}$ & $\begin{array}{c}\text { Expanded } \\
\text { financial and } \\
\text { administration } \\
\text { systems }\end{array}$ \\
\hline 1980s & $\begin{array}{l}\text { Networking } \\
\text { Personal } \\
\text { Computers }\end{array}$ & $\begin{array}{l}\text { Cheaper } \\
\text { storage and } \\
\text { standalone } \\
\text { software } \\
\text { apps }\end{array}$ & $\begin{array}{l}\text { Integrated and } \\
\text { managed care } \\
\text { financial } \\
\text { clinical } \\
\text { systems. }\end{array}$ \\
\hline 1990s & $\begin{array}{l}\text { Competition } \\
\text { and } \\
\text { managed } \\
\text { care offering }\end{array}$ & $\begin{array}{l}\text { Cheaper } \\
\text { hardware } \\
\text { and } \\
\text { software }\end{array}$ & $\begin{array}{l}\text { Expanded } \\
\text { clinical } \\
\text { departmental } \\
\text { solutions }\end{array}$ \\
\hline
\end{tabular}

\begin{tabular}{|c|c|c|c|}
\hline \multirow{2}{*}{$2000 s$} & $\begin{array}{c}\text { More } \\
\text { integration } \\
\text { of outcomes- } \\
\text { based } \\
\text { returns }\end{array}$ & $\begin{array}{c}\text { Mobility } \\
\text { emerging } \\
\text { cloud } \\
\text { computers }\end{array}$ & $\begin{array}{c}\text { Emerging } \\
\text { broad-based } \\
\text { decision } \\
\text { support, data } \\
\text { warehousing } \\
\text { and analytics } \\
\end{array}$ \\
& & & solutions \\
\hline
\end{tabular}

Further beyond: The proposed system would be the TICOS: Treatment Information and Cost Optimisation System, which is designed to be a regulatory body integrated with a cloud based application.

A selected hospital in Greater Noida city of Uttar Pradesh, India, holds some competitive advantage over other traditional hospitals in terms of services offered [12].

Table 2. Performance of the Hospital in respect of treatment

\begin{tabular}{|c|c|c|c|c|}
\hline $\begin{array}{c}\text { Sl. } \\
\text { No. }\end{array}$ & $\begin{array}{c}\text { Types of } \\
\text { treatment }\end{array}$ & $\begin{array}{c}\text { Total } \\
\text { Score }\end{array}$ & $\begin{array}{c}\text { Mean } \\
\text { Score }\end{array}$ & Rank \\
\hline 1. & Cardiology & 11216 & 62.60 & II \\
\hline 2. & Gastroenterology & 9368 & 46.84 & VI \\
\hline 3. & Neurology & 10734 & 53.67 & IV \\
\hline 4. & Gynaecology & 11099 & 55.50 & III \\
\hline 5. & Ortho & 9841 & 49.21 & V \\
\hline 6. & Urology & 8078 & 40.39 & IX \\
\hline 7. & ENT & 9014 & 45.07 & VII \\
\hline 8. & Physiotherapist & 8552 & 42.76 & VIII \\
\hline 9. & Pediatrics & 12520 & 56.08 & I \\
\hline
\end{tabular}

The above table shows that Pediatrics is the main competitive advantage gained by the hospital in question, when compared to traditional hospitals.

\subsection{Cost Comparisons of Basic and Other Medical Services offered by Indian Hospitals}

Institutional care is an emerging component of health care costs in low- and middle-income countries like India [13], but there exists an inadequate knowledge of the costs of different medical services. In India, greater utilisation of hospital services is driven both by rising incomes and by government insurance programmes that cover the cost of inpatient services. The below two tables is the secondary data collected for the treatment wise costs (for both basic as well as other medical services), which are followed by a graphical 
comparison of both types of services. (USD 1=INR 52)

Table 3. Total cost of basic medical services, April 2010March 2011.

\begin{tabular}{|c|c|}
\hline Cost centre & Total cost (INR) \\
\hline \multicolumn{2}{|c|}{ A) Charitable hospital } \\
\hline OPD & $3,427,796$ \\
\hline IPD & $17,166,648$ \\
\hline Emergency & $14,212,450$ \\
\hline Major OT & $8,750,188$ \\
\hline Total operating cost & $43,543,262$ \\
\hline \multicolumn{2}{|c|}{ B) District hospital } \\
\hline OPD & $27,488,691$ \\
\hline IPD & $32,559,127$ \\
\hline Emergency & $12,657,103$ \\
\hline Major OT & $9,436,319$ \\
\hline Total operating cost & $120,388,582$ \\
\hline \multicolumn{2}{|c|}{ C) Tertiary care hospital } \\
\hline OPD & $89,522,217$ \\
\hline IPD & $126,424,853$ \\
\hline Emergency & $67,164,970$ \\
\hline Major OT & $26,918,158$ \\
\hline Total operating cost & $527,923,769$ \\
\hline \multicolumn{2}{|c|}{ D) Private hospital } \\
\hline OPD & $113,231,544$ \\
\hline IPD & $188,115,015$ \\
\hline Emergency & $27,910,526$ \\
\hline Major OT & $60,232,583$ \\
\hline Total operating cost & $715,449,780$ \\
\hline \multicolumn{2}{|c|}{ E) Private teaching hospital } \\
\hline OPD & $53,032,830$ \\
\hline IPD & $58,660,813$ \\
\hline Emergency & $10,742,927$ \\
\hline Major OT & $47,598,213$ \\
\hline Total operating cost & $239,552,971$ \\
\hline
\end{tabular}

\section{Total cost (INR)}

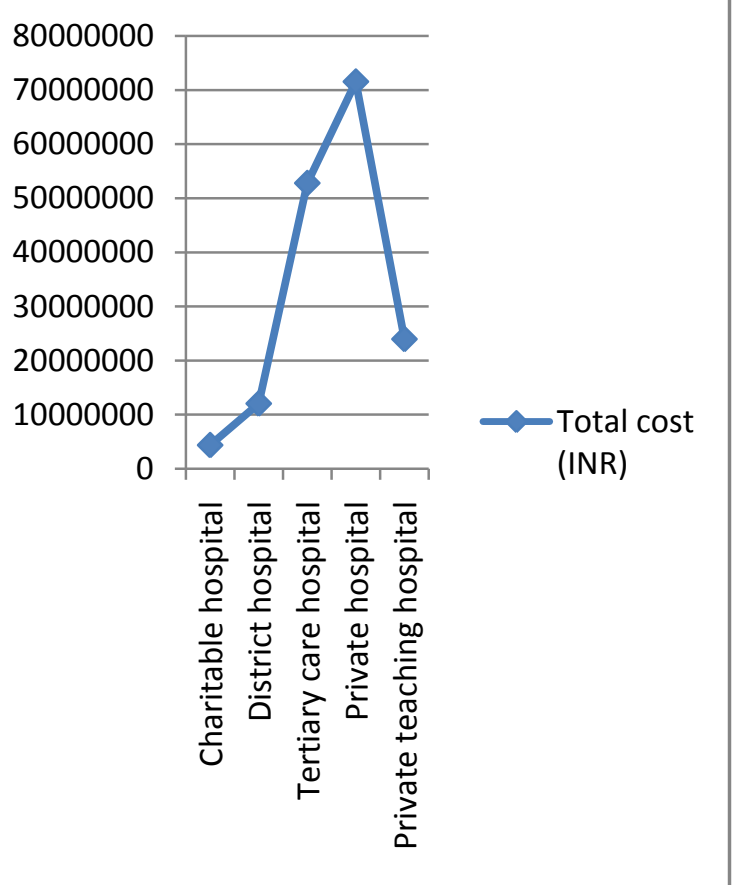

Figure 1: Graphical Plot for Basic Medical Services

Apart from this, it has also been found that human resources are the largest component of a hospital's total operating costs, especially for the government's district and tertiary care hospitals. In most tertiary care institutions, salaries and wages account for as much as 70 percent of the total health budget. Human resources cost is less at the charitable and the private hospital because the salary structure at these hospitals is lower than the prevailing market rate. It may be proposed that ground-level nontechnical support staff can also contribute effectively to the working of the hospital management system. In fact, hospital administrators being aware of the problem can appoint a medical advisor to monitor and strategize the working of the entire system.

Table 4. Total cost of other medical services, April 2010 March 2011.

\begin{tabular}{|c|c|}
\hline Cost centre & Total cost (INR) \\
\hline \multicolumn{2}{|c|}{ A) Charitable hospital } \\
\hline Laboratory & $3,217,667$ \\
\hline Radiology & $1,637,837$ \\
\hline Pharmacy & 947,510 \\
\hline NICU & $5,087,475$ \\
\hline \multicolumn{2}{|c|}{ District hospital } \\
\hline Emergency OT & $1,021,764$ \\
\hline Eye OT & $2,930,282$ \\
\hline IPP OT & $1,304,618$ \\
\hline
\end{tabular}




\begin{tabular}{|c|c|}
\hline Laboratory & $8,825,395$ \\
\hline Pharmacy & $3,670,730$ \\
\hline Physiotherapy & 904,952 \\
\hline ICU & $3,451,709$ \\
\hline NICU & $8,788,146$ \\
\hline Dialysis unit & $3,958,777$ \\
\hline Labour ward & $3,390,972$ \\
\hline \multicolumn{2}{|c|}{ C) Tertiary care hospital } \\
\hline OPD: medicine, cardiology & $33,096,830$ \\
\hline OPD: surgery & $19,499,977$ \\
\hline OPD: eye & $15,782,112$ \\
\hline OPD: orthopaedics & $18,354,932$ \\
\hline IPD: medicine & $39,731,843$ \\
\hline IPD: surgery & $39,404,129$ \\
\hline IPD: eye & $8,366,546$ \\
\hline IPD: orthopaedics & $22,980,449$ \\
\hline Orthopaedics OT & $20,403,797$ \\
\hline Emergency OT & $15,648,684$ \\
\hline All laboratory & $48,509,048$ \\
\hline Microbiology laboratory & $12,092,740$ \\
\hline Biochemistry laboratory & $13,640,794$ \\
\hline Pathology laboratory & $22,775,514$ \\
\hline Radiology & $47,410,516$ \\
\hline Physiotherapy & $7,683,767$ \\
\hline \multicolumn{2}{|c|}{ D) Private hospital } \\
\hline CTOT & $52,506,934$ \\
\hline Laboratory & $36,868,238$ \\
\hline Radiology & $31,054,870$ \\
\hline Pharmacy & $65,879,948$ \\
\hline SICU & $19,091,664$ \\
\hline CTICU & $29,200,747$ \\
\hline RICU & $25,052,733$ \\
\hline MICU & $27,541,425$ \\
\hline ICCU & $24,794,259$ \\
\hline Dialysis unit & $13,969,294$ \\
\hline \multicolumn{2}{|c|}{ E) Private teaching hospital } \\
\hline Gyn OT & 12870851 \\
\hline Laboratory & $9,835,855$ \\
\hline Radiology & $20,872,248$ \\
\hline Pharmacy & $3,004,746$ \\
\hline
\end{tabular}

\begin{tabular}{|c|c|}
\hline Labour room & $4,579,199$ \\
\hline MICU & $7,800,575$ \\
\hline NICU & $4,393,140$ \\
\hline SICU & $6,161,573$ \\
\hline
\end{tabular}

\section{Total cost (INR)}

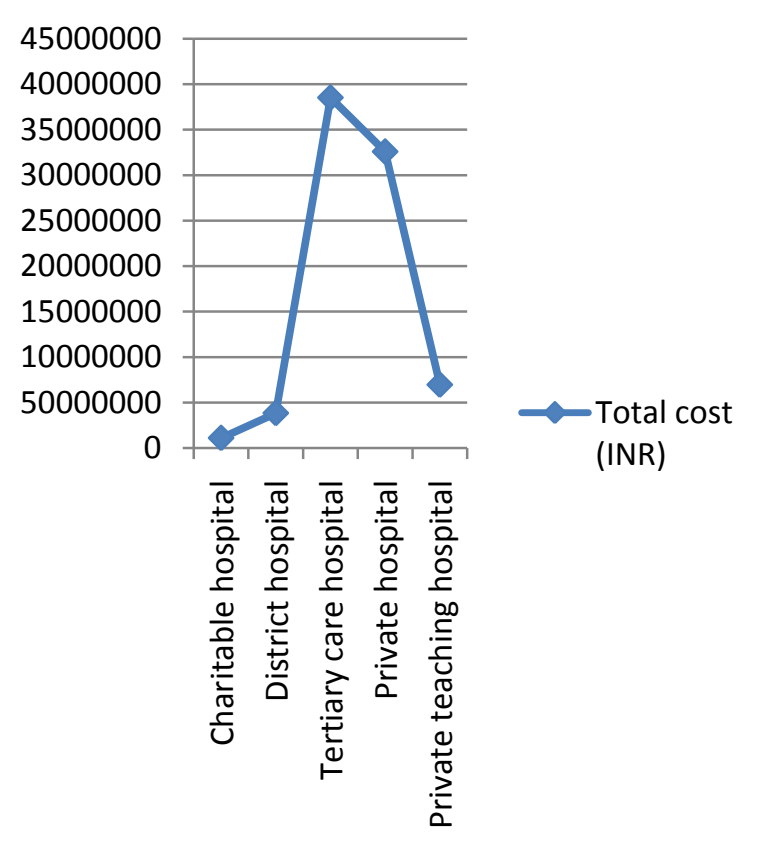

Figure 2: Graphical Plot for Other Medical Services

Table 5. Expansion of Abbreviations Used:

\begin{tabular}{|c|c|c|}
\hline S.no. & Abbreviation & Expansion \\
\hline $\mathbf{1 .}$ & IPD & Inpatient department. \\
\hline $\mathbf{2 .}$ & OPD & Outpatient department. \\
\hline $\mathbf{3 .}$ & OT & Operating theatre. \\
\hline $\mathbf{4 .}$ & CTICU & $\begin{array}{c}\text { Cardiothoracic intensive care } \\
\text { unit. }\end{array}$ \\
\hline $\mathbf{5 .}$ & CTOT & Cardiothoracic operating \\
theatre.
\end{tabular}




\begin{tabular}{|c|c|c|}
\hline 14. & OT & Operating theatre. \\
\hline $\mathbf{1 5 .}$ & RICU & Respiratory intensive care unit. \\
\hline $\mathbf{1 6 .}$ & SICU & Surgical intensive care unit. \\
\hline
\end{tabular}

Thus, from the two graphs of total Cost vs. Hospitals, the slope of the graphs will give us the floor and cap values, followed by the determination of the optimum or average cost. This cost then influences on the average price of the treatment given to patients. Thus, the following section discusses on the information system designed to implement the solution, based on uncertainty theory and compromise effect, resulting in an effective decision making process, for the benefit of the patients.

\section{PROPOSED SYSTEM ARCHITECTURE}

\subsection{Information Systems in Hospitals in the Current Scenario}

At present, a full-fledged Hospital Management System (HMS) that is web-based, is being implemented in a majority of the hospital chains in India. Medinous HMS [14] is one such solution that provides the benefits of streamlined operations, enhanced administration \& control, superior patient care, strict cost control and improved profitability.

Thriving on technology and technical expertise, these products enable customers to improve operational efficiency and gain competitive edge by offering powerful and comprehensive features and ensuring unparalleled simplicity and easy adaptability, keeping the customer in mind.

Quintegra [15], a HMIS based in South India, is yet another revolutionary solution, that has developed several core and supportive modules dedicated to the various departments of the hospital i.e., Bloodbank, Physiotherapy, Dialysis, Pharmacy, Theatre Management, Housekeeping etc. It is powered by SAP Netweaver (a platform that integrates business processes with web service technologies) and follows a multi-level, patient-centered and distributed information system for a superior excellence in delivery.

\subsection{TICOS as a Solution}

The TICOS System can be integrated with the existing information systems in the hospitals as a separate module. It would remain connected with the existing hospital server and would retrieve critical information (unknown) from the IMA/WHO server (the regulatory body whichever is applicable). The system would be integrated via cloud platform. Entities of the HIS-TICOS are as depicted in the implementation diagram (Figure 3).

This information system must utilize a high end software package that can be integrated with the host server of the hospital, and must have a distributed network configuration, well connected through the Local Area Network (LAN). The hospital server must have a high end access to the IMA or the WHO server, through a virtual cloud platform. The system must host the TICOS application and execute it, whenever the doctors are to retrieve treatment information and the customer has an enquiry or a request for an optimal price and to arrive at clarity over the treatment options.

On consultation with the doctor, the patient's family, depending upon the immediate concerns and financial affordability, must be given the right and the privilege to approach a Medical Consultant, who should be to handle and monitor the TICOS system. The Medical Consultant may be appointed as a full time staff of the Hospital in question. On paying heed to the patient's grievance and situation, this consultant must facilitate the patients with the information on the complete treatment service to be offered, clarify queries based on patient enquires and extract the maximum and the minimum price quotes for the particular medical treatment, through the TICOS software, work out the full information retrieval and optimal price, for the service to the customer. In this way, the ambiguity in knowing the process of treatment and its relative costs is eradicated, the patients may be in a relaxed state of mind that will help them to traverse through the path to a speedier healing.

The doctor may also have access to the patient's activity and interaction [16] history with the TICOS system, through a dedicated server network, and the medical consultant must ensure that the corresponding doctor receives this detail from time to time, maintaining utmost confidentiality.

\section{IMPLEMENTATION OF THE TICOS SYSTEM}

The proposed system may be designed and implemented as shown in the following diagram: 


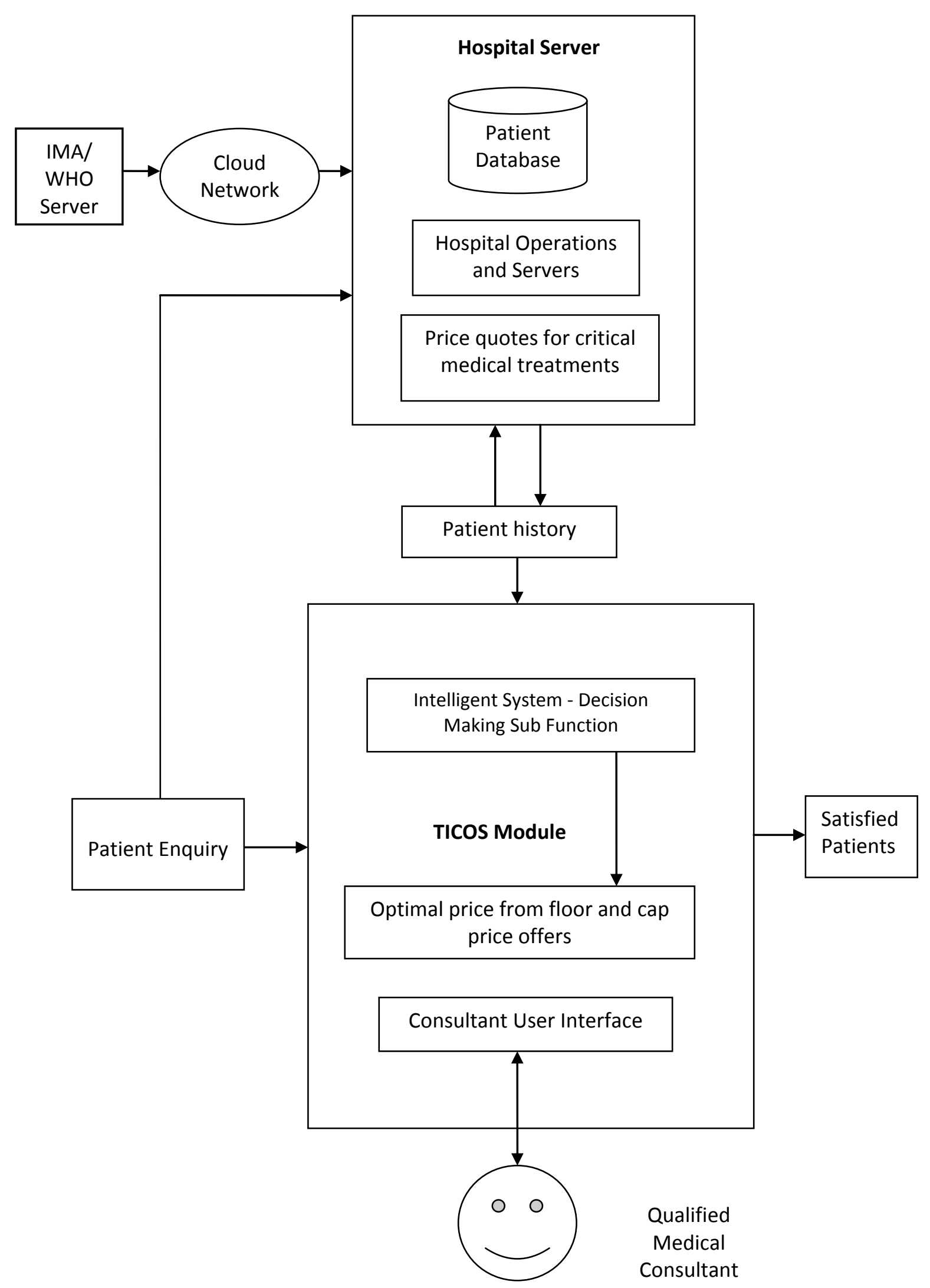

Figure 3: Architecture Diagram 


\subsection{Architecture Description}

The architecture (Figure 3) includes four types of components:

\subsubsection{IMA or WHO Server}

The module embedded is connected with the WHO/IMA server repository in order to bring up-to-date information into the system and ensure authenticity of information via a related regulatory body

\subsubsection{Hospital specific HMS}

The HMS is the information system in the hospital that has been existing already, and it is being included with the module.

\subsubsection{TICOS Module}

The prime module that enables decision making consists of access to patient history $\mathrm{DB}$, price slabs, and has a decision sub function that provides the most optimum choice of treatment in case by case basis. The Module contains AI algorithms to enable this.

\subsubsection{Cloud network}

The connectivity of devices is enabled via the cloud network. This is the most efficient choice as it is long term and cost effective in terms of current usage needs as well as in case of extending the application with respect to future scope.

\section{INTEGRATING TICOS INTO THE CURRENT HOSPITAL SYSTEM}

The TICOS system doesn't require much hosting and implementation costs as it holds only a primary and key entity, the decision making sub function, which controls and executes the entire process.

All that the TICOS system would require would be a trusted medical superintendent who would take responsibility to coordinate with the doctor or physician to obtain the patient history and feed them into the database for easy retrieval.

During the patient interaction and decision making stage, a consultant can be assigned who will take charge of counseling the patient and the family members, follow a fair practice of specifying an optimal cost, and ensure utmost confidentiality in carrying out this process (as optimal cost varies with different people, based on their ability to pay and other external uncontrollable factors like a lack of time, non availability of organ donors, severe blood loss for the patient, other critical complications like internal hemorrhage, coma, cancer or tumor etc.)

Besides, one would also need to ponder over the legal aspect of this TICOS system: it requires a stringent surveillance board that coordinates with health officials in the hospitals as well as health organizations (IMA), perform regular inspections, identify violators of the process and prosecute them as per the law.

\subsection{Advantages and Disadvantages}

The system as a whole enables accurate decision making and price negotiation for a treatment to be done. Complete information scenario and transparency of process is the main advantage of the system. Competitive advantages between hospitals might a factor that gets negatively influenced, in terms of competitive advantage and costs, but the idea is to bring about a fair practice in terms of operating process and pricing across all the private hospitals.

\subsection{Pre-Requisite}

1. A government imposed consensus on private hospitals to embed the system with their existing HMS.

2. Authenticity and safety of data ensured through proper security and firewall mechanism as the system is to work in tandem with regulatory bodies like WHO and IMA (in case of India)

3. A diploma course with exclusive training over the application must be extended and certification for the same must be government recognized. Doctors must refrain from qualifying themselves as consultants, in order to maintain fairness.

4. All operations the consultant and the application as such must be continuously monitored and should be under governmental supervision and control.

5. The architecture and configurations must be compatible to the entire existing HMIS market leader's application.

\section{FUTURE SCOPE}

The system that is now currently focusing on eliminating decision uncertainty in terms of awareness and price slabs, can also be extended to include common symptoms, diagnosis and preliminary preventive measures database (not the actual treatment) that can be accessed by the common people to be aware of the know-how and current health issues and for the doctors to update the information via consultants or by themselves.

Separate modules one for private and other for government hospitals can be initiated so that there is no interference between their operations, yet there exists uniformity.

An add-on feature would be also to encourage virtual live "chat-rooms" with the medical consultant, with the facility to track appointments through mobile alerts and apps, if TICOS may be extended to mobile technology as well.

\section{CONCLUSION}

In a nutshell, decision uncertainty is to be eliminated in the health care sector especially the private hospitals. All the existing HMS focus only on, a robust centrally controlled system, enhancing the current IT infrastructure in medical institutions, deliver patient experience and care exceeding expectations. A rigorous information system to help customers find the complete information and affordable price for a medical treatment is yet to be explored. Such a system requires a transparent and genuine implementation by leading Health Organizations like WHO and IMA, who can administer and monitor this solution in various leading hospital chains across India. Further, an absolute cost and effort controlling factor about TICOS is the significant reduction in the waiting hours and duration of consultation on a patient's initial visit, thereby reducing the overhead for doctors as well. Overall, this system will be a facilitator of a transparent, consistent, informative process (inclusive of the psychological aspects of the patients, which is the prime concern for customer satisfaction in a service sector) thus enabling the efficiency in terms of time and efforts in a holistic manner. 


\section{ACKNOWLEDGMENTS}

Our thanks go to our guide, Dr. A. Vasumathi, whose advices and suggestions during the course of the development and research activities helped in the preparation of this paper.

\section{REFERENCES}

[1] Angela Morrow (2012) "Making Difficult Decisions: Identifying Goals of Care, by Dying, Funerals \& Grief Expert"[Online]Availablehttp://dying.about.com/od/ethic sandchoices/a/decisions.htm

[2] HISPIndia,CompanyWebsite: https://www.hispindia.org/

[3] Cognizant Healthcare Solutions Company Website: http://www.cognizant.com/healthcare

[4] Birlamedisoft Healthcare Software Developers, Company Website: http://www.birlamedisoft.com/

[5] Making Effective Decisions in High Uncertainty [Online] Available: http://www.decision-making solutions.com/decision-making-in-uncertainty.html

[6] Decision-Making under Uncertainty [Online] Available: http://www.cs.berkeley.edu/ jordan/muri/

[7] Mohamed A. Ahmed, Talal M. Alkhamis (2009) "Simulation optimization for an emergency department healthcare unit in Kuwait" In European Journal of Operational Research, Volume 198, Issue 3, Pages 936942.

[8] Wei Zhoua, Selwyn Piramuthu (2010) "Framework, strategy and evaluation of health care processes with RFID”, In Elsevier-Volume 50, Issue 1, 222-233.

[9] Banks I. (2010) "Self Care of Minor Ailments: A Survey of Consumer And Healthcare Professional Beliefs And Behaviour (1):1-13.

[10] Karl Claxton, Mike Paulden, Hugh Gravelle, Werner Brouwer and Anthony J. Culyer (2010) "Discounting and Decision making in the economic evaluation of healthcare technologies" May 12, 2010.

[11] Paul K. J. Han, MD, MA, MPH, William M. P. Klein, Neeraj K. Arora (2009) "Varieties of Uncertainty in Health Care: A Conceptual Taxonomy" In International Conference on Communication in Healthcare, Miami, Florida, October 4, 2009.

[12] Sarojkumar Dash (2010) "Managing Customer Relationships In Private Health Care Facilities - A Study With Reference To Greater Noida City Of Uttar Pradesh", In QUEST Journal of Management and Research-Volume 1(2), 29-41.

[13] SusmitaChatterjee, CarolLevin and RamananLakminaray an (2013) "Unit Cost of Medical Services at Different Hospitals in India" In PLoS ONE (An Open Access Journal), Volume 8, Issue 7.

[14] MedinousCompanyWebsite:http://www.medinous.com/a boutus.html

[15] QuintegraSolutionsCompanyWebsite:http://quintegrasol utions.com/Quintegra\%20HMIS.pdf

[16] Erwin W. Hans, Mark van Houdenhoven, Peter J. H. Hulshof (2011) "A Framework for Healthcare Planning and Control", 24 Nov 2011. 